\title{
Combating Accidental Microbial Episodes by Back-Ground Chlorine Residuals in a Scaled-up Distribution Network (Rig) Using a Central Composite Design (CCD)
}

\author{
S. Rasheed, I. Hashmi, Q. Zhou, J. K. Kim, and L. C. Campos
}

\begin{abstract}
A quadratic model $(\boldsymbol{p}<\mathbf{0 . 0 0 0 1})$ was developed by using a central composite design of 50 experimental runs (42 non-center +8 center points) to assess the efficiency of background chlorine residuals in combating accidental microbial episodes in a scaled-up distribution network (DN) (rig). A known amount of background chlorine residuals were maintained in the DN and a required number of bacteria, Escherichia coli K-12 strain, was introduced by an injection port in the pipe-loop system. Samples were taken at various time intervals at different pipe lengths. A spread-plate count was performed to count the bacterial number. Microbial concentration and time $(p<0.0001)$, pipe length $(p<0.022)$, background chlorine residuals $(p<0.07)$ and time $^{2}(p<0.09)$ were observed as significant factors. The model that was developed was significant. The ramp function of variables shows that, at the microbial count of $10^{\wedge} 6$, at $0.76 \mathrm{~L} / \mathrm{min}$, with a pipe length of 133 meters, a back ground residual chlorine of $0.16 \mathrm{mg} / \mathrm{L}$ was enough for the complete inactivation of a microbial episode in approximately 18 minutes.
\end{abstract}

Index Terms - Central composite design (CCD), distribution network, Escherichia coli, residual chlorine.

\section{INTRODUCTION}

The purpose of a water supply-distribution system is to deliver safe, potable water which is adequate in quantity and acceptable in terms of taste, odor and appearance [1]. Surface run-off, cross-connection and the leakage of sewage disposal systems as well as septic tanks' wrecked or leaking pipes, back siphonage from a plumbing fixture or cross-connection into a water supply line and intermittent water supply are some other reasons behind the bacterial nemesis of the drinking-water industry, especially in developing countries [2].These external contamination events can act as a source of inoculum, introducing nutrients and resulting in the decrease of residual disinfectant concentrations within the distribution system, causing degradation of water quality. A poorly maintained distribution system can act as a vehicle for

Manuscript received March 15, 2014; revised June 10, 2014. This work was supported by International Research Support Initiative Programme of Higher Education Commission, Pakistan (IRSIP-HEC, Pak).

S. Rasheed and I. Hashmi are with the Institute of Environmental Sciences and Engineering, School of Civil and Environmental Engineering, National University of Sciences and Technology, Islamabad, Pakistan (e-mail: sajidarasheed@iese.nust.edu.pk,imran.hashmi@iese.nust.edu.pk).

Q. Zhou, G. K. Kim, and L. Campos are with University College London, London, UK (e-mail: qizhi.zhou@ucl.ac.uk, j.k.kim@ucl.ac.uk, 1.campos@ucl.ac.uk). pathogens transmission and may even contribute significantly to gastrointestinal diseases in the community [3]. Nowadays, preserving the water quality throughout the water distribution system is therefore the most challenging technological issue. An important mitigation measure that can be employed to protect against intentional or accidental microbial intrusion/contamination is the maintenance of suitable chlorine residuals throughout the distribution network, often regarded as "residual maintenance strategy" [4]. Chlorine provides the residual barrier the distribution system worldwide. The recommended chlorine residual for water, that is centrally treated, at the point of delivery should fall within $0.2-0.5 \mathrm{mg} / \mathrm{l}$ [5]. This residual chlorine concentration reduces the risk of general contamination by the accidental entry of microorganisms due to either back siphonage or to a re-growth of the microorganism within the distribution network as breakage from the biofilm [6]. Thus, controlling this concentration in drinking water is a very important aspect, since the decrease in its level below that recommended may cause a secondary development of microorganisms [7]. Changes in chlorine residuals can be used as indicators of microbial contamination [8]. Experience has shown that the maintenance of the chlorine residual cannot be relied upon to totally prevent the occurrence of bacteria. As water flows from the treatment plant to the consumer's tap, the water quality deteriorates because of a decreasing residual chlorine concentration, especially for 'long residence' times. It was observed that, as the chlorine residual decreased from $4.6 \mathrm{ppm}$ at the plant to $0.2 \mathrm{ppm}$ at the household, there was a statistically significant increase in total and thermo tolerant coliforms [4]. Although chlorine residuals greatly contribute to the inactivation and re-growth of indicator bacteria, i.e. faecal coliforms in the pipeline, the question awaiting an answer, is the level of inactivation at the recommended levels of chlorine residual by the World Health Organization (W.H.O) and the effect of environmental factors upon the efficiency of background chlorination and the required time to combat the microbial attack [9]. Furthermore, the ability of disinfectant residuals to inactivate microorganisms between the time that they enter the distribution system and the time they reach the consumer is still to be analyzed. So the present study was designed to quantitatively assess a distribution system's vulnerability against microbial intrusion and to evaluate the efficiency of background residual chlorine in combating any accidental microbial event from occurring in the system and the factors that contribute towards its failure in connection with the microbial episode. 


\section{MATERIALS AND METHOD}

\section{A. Design of Experiment (DoE) by the Central Composite Design (CCD)}

With this technique, the main objective is to optimize the response surface that is influenced by various process parameters. It also quantifies the relationship between the controllable input parameters and the obtained response surfaces [10]. Design Expert (Trial Version 9, MN, USA) was used as the tool for the Design of the Experiment (DoE). The objective of DoE is the selection of the points where the response should be evaluated. A CCD consisting of a full factorial design with 30 experiments was selected to simultaneously optimize the levels of these variables in attaining the best system performance. The independent variables were: pipe length, microbial concentration, flow rate, background chlorine residuals and time, as depicted in Table I. The lower values are coded as -1 and the higher values are coded as +1 .

TABLE I: INDEPENDENT VARIABLES AND THEIR LOW/ HIGH-LEVEL VALUES BY THE CCD IN THE DESIGN EXPERT

\begin{tabular}{ccccccc}
\hline $\begin{array}{c}\text { Coded } \\
\text { Values }\end{array}$ & $-\alpha$ & -1 & 0 & +1 & $+\alpha$ \\
\hline \begin{tabular}{c} 
Variables \\
\hline $\begin{array}{c}\text { Pipe } \\
\text { Length }\end{array}$
\end{tabular} & A & 22.5 & 67.5 & 112.5 & 157.5 & 202.5 \\
$\begin{array}{c}\text { Microbial } \\
\text { Conc. }\end{array}$ & B & $10^{\wedge} 5$ & $10^{\wedge} 6$ & $10^{\wedge} 7$ & $10^{\wedge} 8$ & $10^{\wedge} 9$ \\
$\begin{array}{c}\text { Flow Rate } \\
\text { Backgrnd. }\end{array}$ & $\mathrm{C}$ & 0 & 0.5 & 1 & 1.5 & 2 \\
$\begin{array}{c}\text { Chlorine } \\
\text { Time }\end{array}$ & $\mathrm{D}$ & 0.05 & 0.15 & 0.25 & 0.35 & 0.45 \\
\hline
\end{tabular}

\section{B. The Distribution Rig}

A laboratory-scale distribution network (proto-type rig) was established consisting of HDPE pipe of 220 meters in two concentric loops and a main water reservoir with a flow meter to regulate the flow within the network. Nine sampling ports were provided (22.5 meters apart) in order to collect the samples at various time intervals (Fig. 1). The loop network is different from a single pipe and a parallel pipe. The number of paths, the water flow from water sources to the observatory point, depends on the amount of looping. De-chlorinated tap water was used (by employing an injection syringe) as the medium to introduce a bacterial event.
Commercial sodium hypochlorite(10.5\%) was freshly prepared and different dilutions were applied as per the experimental requirements. For the disinfection of the suspended bacteria, E. coli, K-12 strains were grown on agar spread plates at $37^{\circ} \mathrm{C}$ for 24 hours. The bacterial culture was washed twice with phosphate buffer and centrifuged at $4,500 \mathrm{~g}$ to get rid of any agar remnants. A measured quantity of $10^{\wedge} 6,10^{\wedge} 7,10^{\wedge}$ 8and $10^{\wedge} 9$ was introduced through an injection port when a required background chlorine level was maintained. The flow rate was uniformly kept by using a flow meter and samples were collected at various pipe lengths. The residual chlorine was quenched by adding $0.01 \mathrm{~N}$ sodium thiosulphate $\left(\mathrm{Na}_{2} \mathrm{~S}_{2} \mathrm{O}_{3}\right)$ to cease further disinfection reaction. Serially-diluted sub-samples of each suspension were plated as spread-plate counts and incubated for 24 hours at $37{ }^{\circ} \mathrm{C}$. The 'free' chlorine was measured with a Spectroquant Picco colorimeter according to standard methods [11].

\section{RESUlTS AND DISCUSSION}

The main objective was to evaluate the efficiency of background chlorine in combating an accidental or a deliberatelyinduced microbial event in a scaled-up distribution network. ANOVA analysis was performed and a quadratic model was developed with a significant $p$ value $<0.0001$. Values of 'Prob $>$ F' less than 0.05 indicate model terms are significant and values greater than 0.1 indicatethe model terms are not significant [12]. The terms A, B, D and E are significant with $p<0.022,0.0001,0.07$ and 0.0001 respectively. The coefficient of determination(R2) is $81 \%$,ensuring a satisfactory agreement of the quadratic models to the experimental data. Predicted R-square of 0.5015 is in reasonable agreement with Adj. R- square of $0.6948 \mathrm{i}$-e., the difference is less than 0.2. Adeq. Precision measures signal to noise ratio. A ratio greater than 4 is required which is 10.178 in this case i.e., the model may be used to navigate the signal. PRESS is a measure of how well the model predicts the responses in new experiments. Small PRESS is recommended [13]. The lack of fit was observed insignificant $(p=0.842)$ which describes the variation in the data around the fitted model. If the model does not fit the data well, the lack of fit will be significant, i-e., $p<0.05$. (Table II).

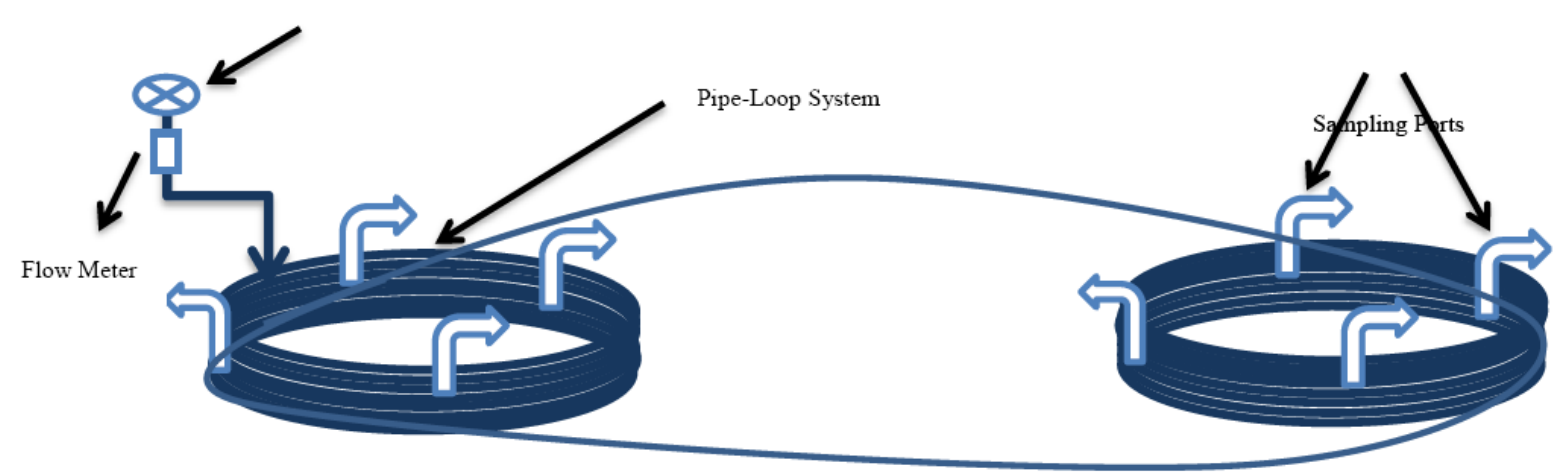

Fig.1. Layout of the Prototype distribution network (rig).

\section{A. Effect of Various Back Ground Chlorine Concentration (BGCC)}

Various background chlorine levels were analyzed, as given in Table I. Observing Fig. 2, it is evident that, with higher levels of background chlorine (BGC), more disinfection is achieved at a given time and distance in the loop system. The BGCL of 0.05 achieved the minimum disinfectionwhile $0.45 \mathrm{mg} / \mathrm{L}$ achieved the maximum 
efficiency of inactivation, approximately 28 minutes after the intrusion episode. It is clear that, for efficient disinfection, a large amount of BGCL is required and still takes almost one-half hour of reaction time. The 3-D surface plots and contour graphs provide a method to visualize the relationship between responses and experimental levels of each variable and the type of interactions between two test variables (Fig. 3 and Fig. 4). The results are in accordance with Gagnon et al.,
[14] who recommended a free chlorine residual of $0.6 \mathrm{mg} / \mathrm{L}$ to control bacterial growth in distribution systems. So it may inferred that a disinfectant residual can guard against only a small amount of reintroduced pathogens, and may easily be overcome by high concentrations of be inferred that a disinfectant residual can only guard against a small amount of re-introduced pathogens and may be easily overcome by high concentrations of contaminants.

TABLE II: ANALYSIS OF VARIANCE (ANOVA) FOR MICROBIAL DISINFECTION BY BACKGROUND CHLORINATION

\begin{tabular}{|c|c|c|c|c|c|}
\hline Source & Sum of Squares & Df & Mean Square & F Value & $\begin{array}{c}\text { P Value } \\
\text { Prob. }>\text { F }\end{array}$ \\
\hline Model & 420.25 & 20 & 21.01 & 8.53 & $<0.0001$ \\
\hline A-Pipe Length & 10.71 & 1 & 10.71 & 5.06 & 0.022 \\
\hline B-Microbes & 232.15 & 1 & 232.15 & 72.67 & $<0.0001$ \\
\hline C-Flow Rate & 0.52 & 1 & 0.52 & 0.16 & 0.6891 \\
\hline D-Background Cl & 10.90 & 1 & 10.90 & 3.41 & 0.0749 \\
\hline E-Time & 114.36 & 1 & 114.36 & 35.8 & $<0.001$ \\
\hline $\mathbf{A B}$ & 8.08 & 1 & 8.08 & 2.53 & 0.1225 \\
\hline $\mathrm{AC}$ & 0.66 & 1 & 0.66 & 0.21 & 0.6535 \\
\hline AD & 5.29 & 1 & 5.29 & 1.66 & 0.2084 \\
\hline $\mathbf{A E}$ & 1.29 & 1 & 1.29 & 0.40 & 0.5297 \\
\hline BC & 0.090 & 1 & 0.090 & 0.028 & 0.8680 \\
\hline BD & 0.028 & 1 & 0.028 & $8.195 \mathrm{E}-003$ & 0.9254 \\
\hline BE & 0.32 & 1 & 0.32 & 0.10 & 0.7524 \\
\hline CD & 6.73 & 1 & 6.73 & 2.11 & 0.1575 \\
\hline $\mathbf{C E}$ & 0.74 & 1 & 0.74 & 0.23 & 0.6340 \\
\hline DE & 2.16 & 1 & 2.16 & 0.68 & 0.4179 \\
\hline A2 & 0.65 & 1 & 0.65 & 0.20 & 0.6541 \\
\hline B2 & 0.014 & 1 & 0.014 & $4.241 \mathrm{E}-003$ & 0.9485 \\
\hline $\mathrm{C2}$ & 1.07 & 1 & 1.07 & 0.33 & 0.5675 \\
\hline D2 & 4.68 & 1 & 4.68 & 1.47 & 0.2358 \\
\hline E2 & 9.43 & 1 & 9.43 & 2.95 & 0.0964 \\
\hline Residual & 92.64 & 29 & 3.19 & ----- & ---- \\
\hline Lack of Fit & 59.97 & 22 & 2.73 & 0.58 & 0.8421 \\
\hline Pure Error & 32.67 & 7 & 4.67 & ---- & ---- \\
\hline Corr. Total & 512.90 & 49 & ---- & --- & --- \\
\hline Std Dev. & 1.79 & Mean & 11.83 & C. V \% & 15.11 \\
\hline R-Square & 0.8194 & Adj. R square & 0.6948 & Pred. R Square & 0.5015 \\
\hline PRESS & 255.67 & & & Adeq. Precision & 10.178 \\
\hline
\end{tabular}

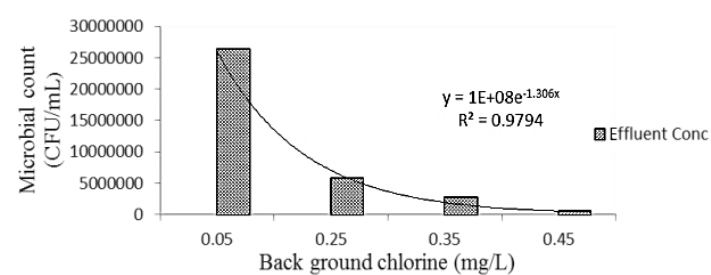

Fig. 2. Effect of various background chlorine residuals on accidental microbial intrusion.

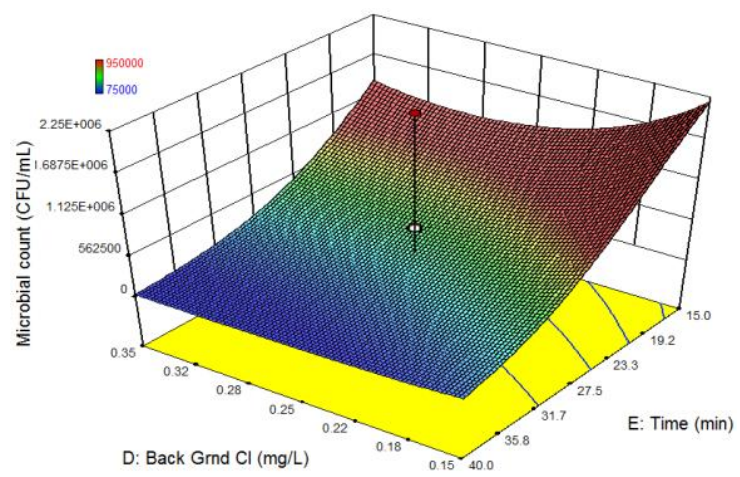

Fig. 3. 3-D response surface graph showing the effect of back ground chlorination with time.

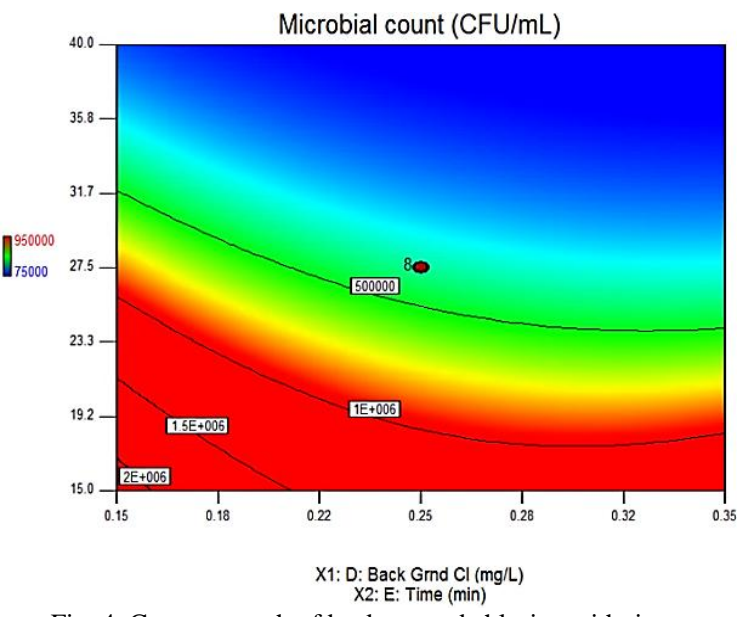

Fig. 4. Contour graph of back ground chlorine with time.

\section{B. The Effect of Pipe Length}

The distance travelled by the microbial plume was observed to see the effect of WHO limit of $0.25 \mathrm{mg} / \mathrm{L} \mathrm{BGCL}$ in a laminar flow. The graph shows that more the distance covered by the plume, more the disinfection achieve 
dirrespective of no mixing of water in the pipe (See Fig. 5).

The long distance is indirectly providing the contact time between the intruder microbes and the back ground chlorine resulting in efficient disinfection. Similar results are also mentioned by other researchers [15].

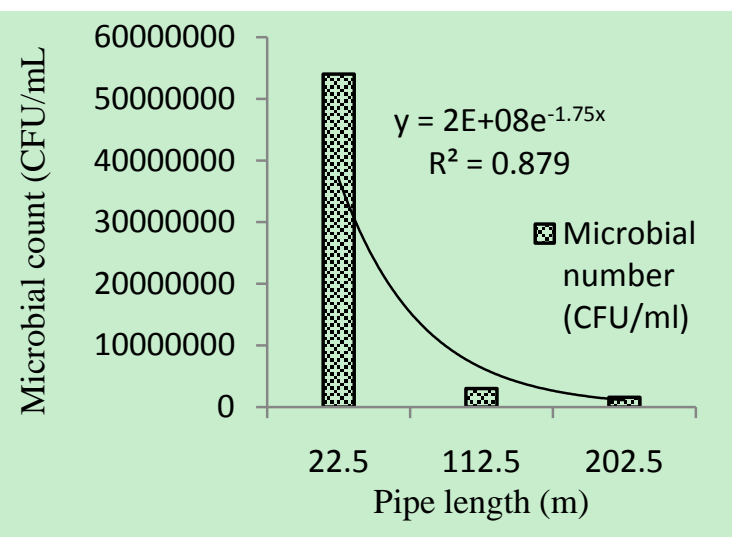

Fig. 5. Decrease of microbial count with increasing pipe.

\section{The Effect of Flow Rate}

Various flow rates were analyzed to observe their effect on microbial inactivation in a distribution network. The flow rate indirectly related to the contact time between microbes and background chlorine.

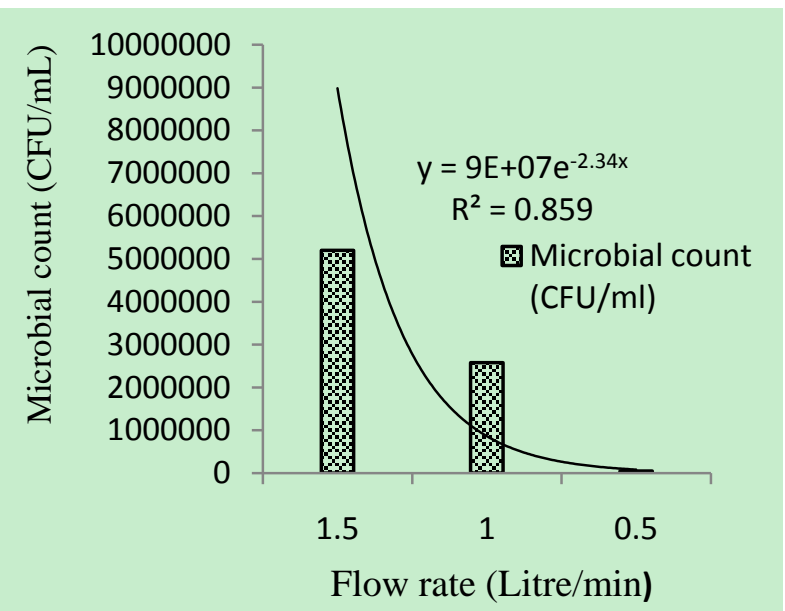

Fig. 6. Effect of flow rate on microbial inactivation.

The more time that it takes water to reach the sampling point, more is the contact time available for background chlorine to complete the disinfection reaction (Fig. 6).

$\operatorname{Ln}(\mathrm{CFU} / \mathrm{mL})=11.90-0.66 \mathrm{~A}+2.32 \mathrm{~B}-0.11 \mathrm{C}-0.50 \mathrm{D}$

$+1.62 \mathrm{E}+0.50 \mathrm{AB}+0.14 \mathrm{AC}+0.20 \mathrm{AE}+0.053 \mathrm{BC}-$

$0.0-0.10 \mathrm{BE}+0.46 \mathrm{CD}-0.15 \mathrm{CE}-0.26 \mathrm{DE}-0.11 \mathrm{~A}^{2}-0.01630 \mathrm{~B}^{2}$

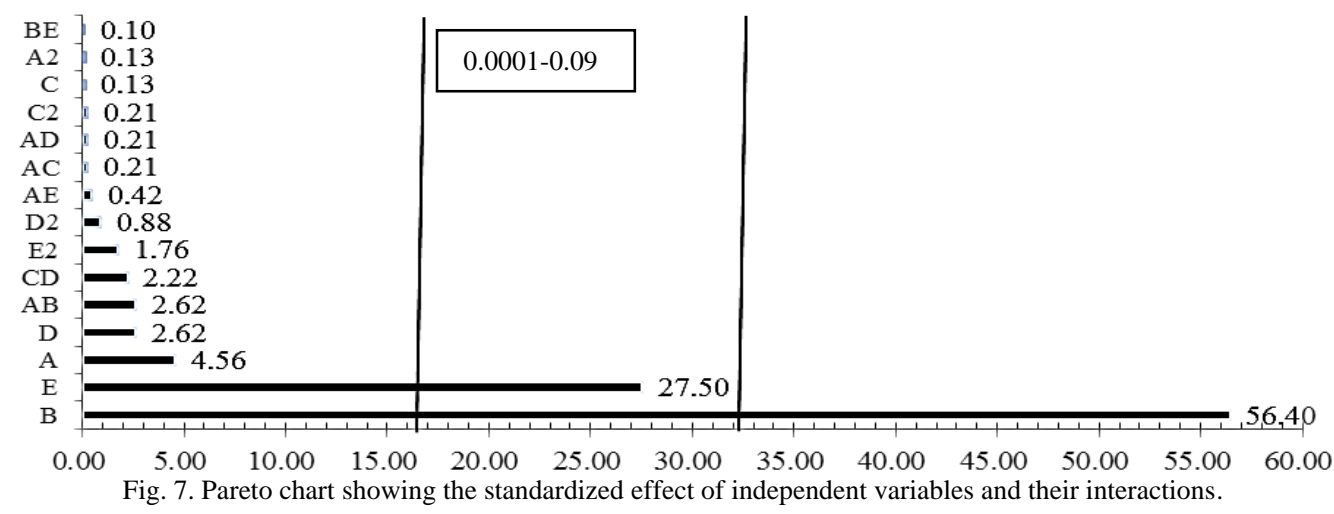

The most important factors which contribute to the disinfection of microbial episodes in the distribution network are presented in the Pareto chart shown in Fig. 7. Among all factors, the "number of microbes" (B) with $56.40 \%$ of the total factors' contribution, contributes the most towards the back ground chlorine's failure to combat the accidental event.

Then "time" (E), "pipe length" (A) and "background chlorine" (D) are influential in their efficiency of a distribution network's disinfection besides $\mathrm{AB}, \mathrm{CD}, \mathrm{E}^{2}$ and $\mathrm{D}^{2}$ respectively.

The model's terms given in Table III are summarized in the form of Equation 1 as follows:
The Eq. 1 reduces to Eq. 2 based on p values depicted in Response Table III, as given under:

$$
\begin{aligned}
& \operatorname{Ln}(\mathrm{CFU} / \mathrm{mL})=11.90-0.66 \mathrm{~A}+2.32 \mathrm{~B} \\
& -0.11 \mathrm{C}-0.50 \mathrm{D}+1.62 \mathrm{E}-0.41 \mathrm{E}^{2}
\end{aligned}
$$

The equation describes the effect of most influential factors very well, depicting the microbial episode as the main factor in the failure of distribution system and a main causative agent in the spread of water borne diseases. The other factors are pipe length, flow rate and background

\begin{tabular}{|c|c|c|c|c|c|c|c|}
\hline Response & Intercept & A & B & C & D & $E$ & $\mathrm{E}^{\wedge} 2$ \\
\hline Ln(Micrba on)... & \multirow[t]{2}{*}{11.8981} & -0.657201 & 2.31509 & -0.109756 & -0.501753 & -1.62492 & -0.411965 \\
\hline$p=$ & & 0.0220 & $<0.0001$ & 0.6891 & 0.0749 & $<0.0001$ & 0.0964 \\
\hline Residual hoie... & \multirow[t]{2}{*}{0.1462} & -0.0113191 & 0.00262067 & 0.00401853 & 0.0522525 & 0.0191442 & \\
\hline$p=$ & & 0.3406 & 0.8245 & 0.7340 & $<0.0001$ & 0.1104 & \\
\hline Legend & & $p<.01$ & $.01<=p<.05$ & $.05<=p<.10$ & $p>=10$ & & \\
\hline
\end{tabular}
chlorine residuals and time. 


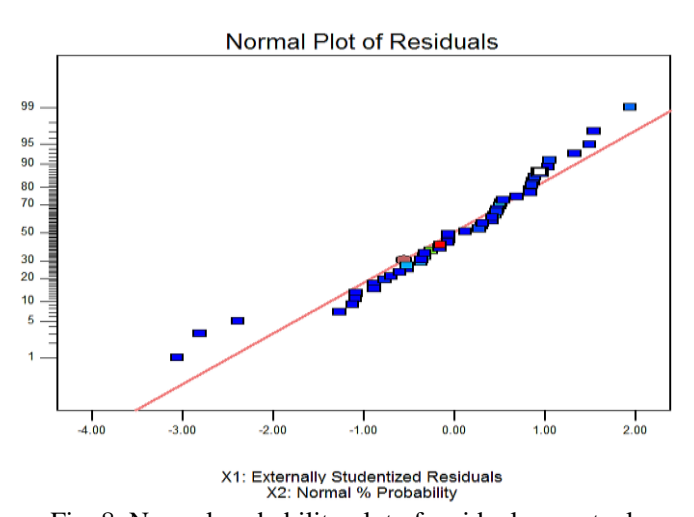

Fig. 8. Normal probability plot of residuals vs actual.

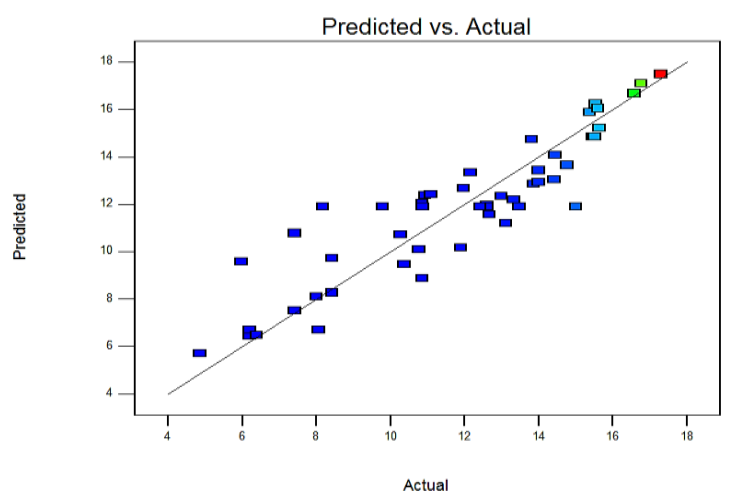

Fig. 9. Plot of predicted vs actual values by applied model.

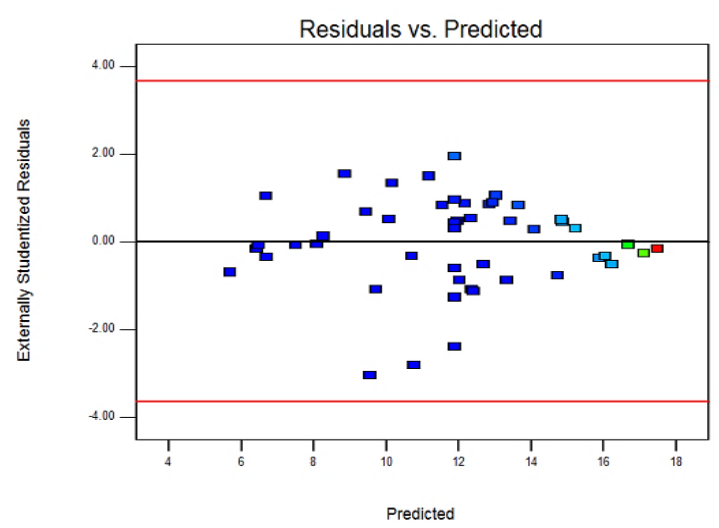

Fig. 10. Plot of predicted vs actual values by applied model.

\section{VALIDATION OF THE MODEL}

Graphical and numerical methods, as a primary tool and confirmation for graphical techniques were used to validate the model described by [16]. The normal probability plots of the residuals and the plots of the actual versus the predicted response in Fig.8and Fig. 9 respectively, revealing that the residuals generally fall on a straight line showing that experimental data is in full agreement with the predicted values. The predicted values were found to be statistically similar to the actual measured values, based on the plotted probability plot. It also implies that the errors are distributed normally. So the developed model was considered to be accurate and reliable for predicting the inactivation efficiency of background chlorine residuals against accidental microbial episode. In Fig. 9, all points are scattered around the straight line showing a pattern and no unusual shape. This implies that the model proposed is adequate to predict the TTHMs formation with various precursors discussed. The plot of residuals vs predicted plot that the experimental values and model predicted values fits very well (Fig. 10).

\section{NUMERICAL OPTIMIZATION}

To optimize the level of each factor for maximum response "numerical optimization" process was employed. It is the combination of different optimized parameters, which gave maximum response it finds one or more points in the factor's domain that would maximize this objective function. The numerical optimization process involves combining the goals into an overall desirability function(D), an objective function that ranges from zero outside of the limits to one at the goal [12].Here the main objective was to evaluate the efficiency of background chlorination to inactivate microbial intrusion in a scaled-up distribution rig (network).

The ramp of variables shows that, at the microbial count of $10^{\wedge} 6$, at $0.76 \mathrm{~L} / \mathrm{min}$ and background residual chlorine of $0.16 \mathrm{mg} / \mathrm{L}$ and a pipe length of 133 meters, the complete inactivation can be achieved in 18 minutes. The $\mathrm{D}=1$ gives the maximum inactivation at the given conditions depicted in the ramp function in Fig. 11.

The present study and mathematical model gave a good measure of the effect of non-point source contamination on water quality and efficiency of back ground chlorine residuals to combat the accidental intrusion of microbes. More studies are required in this regard to monitor and manage the accidental contamination and combating strategies to provide safe drinking water to the community.

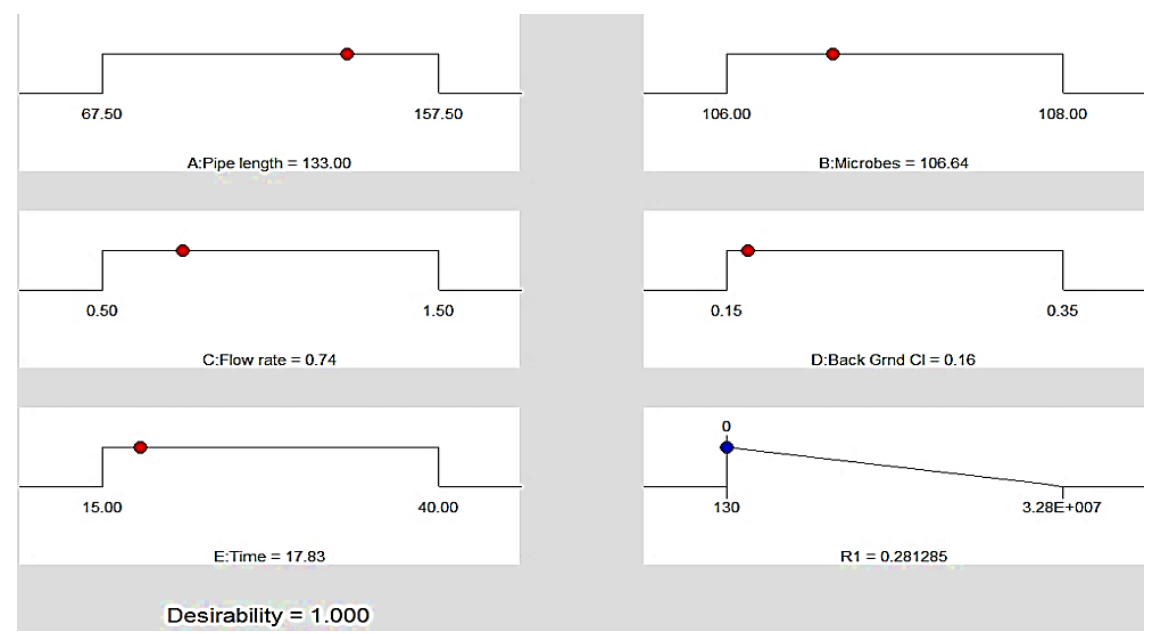

Fig. 11. Ramp function for maximum inactivation when variables were studied simultaneously at desirability $\mathrm{D}=1$. 


\section{REFERENCES}

[1] E. L. Lee and K. J. Schwab, "Deficiencies in drinking water distribution systems in developing countries," Journal of Water and Health, vol. 3, no. 2, pp. 109-127, 2005.

[2] I. Hashmi, S. Farooq, and S. Qaiser, "Chlorination and water- quality monitoring within a public-drinking water supply in the rawalpindi cantt (westridge and tench) area," Environ. Monit. Assess., vol. 158, pp. 393-403, 2009.

[3] D. E. Helbling and J. M. VanBriesen, "Continuous monitoring of residual chlorine concentrations in response to controlled microbial intrusion in a laboratory-scale distribution system," Water Research, vol. 42, 2008.

[4] M. P. Propato and J. G. Uber, "The vulnerability of water- distribution systems to pathogen intrusion:how effective is a disinfectant residual?" Environ. Sci. Technol., vol. 38, pp. 3713-3722, 2004.

[5] WHO, Guidelines for Drinking-Water Quality, 4th ed. World Health Organization, Geneva, pp. 1-541, 2011.

[6] S. Choudhury, P. Champagne, and P. J. J. McLellan, "Investigating the effects of bromide ions on trihalomethanes and developing a model for predicting bromodichloromethanein drinking water," Water Research, vol. 44, no. 7, pp. 2349-2359, 2010.

[7] R. M. Clark, "Chlorine fate and transport in drinking- water distribution systems: results from experimental and modeling studies," Frontiers of Earth Science, vol. 5, no. 4, pp. 334-340, 2011.

[8] S. Srinivasan, G. W. Harrington, I. Xagoraraki, and R. Goel, "The factors affecting bulk to the total bacteria ratio in drinking-water distribution systems," Water Research, vol. 42, no. 13, pp. 3393-404, Jul. 2008.

[9] A. Y. Karikari and J. A. Ampofo, "The chlorine treatment effectiveness and physico-chemical and bacteriological characteristics of treated water supplies in the distribution networks of the Accra-Tema, Metropolis, Ghana," Appl. Water Sci., vol. 3, pp. 535-543, 2013.

[10] B. M. Almeida, R. E. Santelli, E. P. Oliveira, L. S. Villar, and L. A. Escaleira, "Response-Surface Methodology (RSM) as a tool for optimization in analytical chemistry," Talanta, vol. 76, pp. 965-977, 2008.

[11] APHA, The Standard Methods for the Examination of Water and Wastewater, Washington: American Public Health Association, 2005

[12] A. Kohli and H. Singh, "The optimization of processing parameters in induction hardening using response-surface methodology," Sadhana Indian Acad. of Sciences, vol. 36, no. 2, pp. 141-152, 2011.

[13] Y. Zulkifli and Masrianto, "The response-surface methodology approach to optimizing process variables for the densification of rice straw as a rural-alternative solid fuel," J. Applied Sci., vol. 11, no. 7, pp. 1192-1198, 2011.

[14] G. A. Gagnon, H. le` ne Baribeau, S. O. Rutledge, R. Dumancic, A. Oehmen, C. Chauret, and S. Andrews, "Practical paper, disinfectant efficacy in distribution systems: a pilot-scale assessment," Journal of Water Supply: Research and Technology, vol. 57, no. 7, pp. 507-518, 2008.

[15] S. Bishankha, D. R. Bhatta, D. R. Joshi, and T. P. Joshi, "The assessment of the microbial quality of chlorinated drinking tap water and the susceptibility of gram negative bacterial isolates towards chlorine," The Kathmandu University Journal of Science, Engineering And Technology, vol. 9, no. 1, pp. 222-229, July2013.

[16] T. K. Trinh and L. S. Kang, "Application of response surface method as an experimental design to optimize coagulation tests," Environ. Eng. Res., vol. 15, no. 2, pp. 63-70, June 2010.

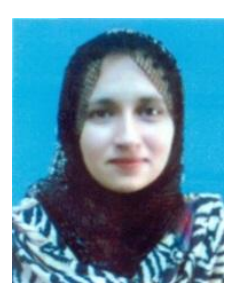

S. Rasheed is a Ph.D. scholar in environmental engineering at Institute of Environmental Sciences and Engineering, School of Civil and Environmental Engineering, National University of Sciences and Technology, Islamabad. She earned her MS degree in environmental engineering in 2009 and M.Phil degree in biochemistry in 2006 from Quaid-e-Azam University, Islamabad, Pakistan.

She has worked as a research assistant and research associate in the same institute in drinking water monitoring group. She is working on optimization of drinking water chlorination system and its dynamic modeling using pathogenic bacteria as model microorganisms. Her research findings on drinking water disinfection have been published in prestigious international and national journals, conferences and seminar proceedings. She is also a visiting faculty for public health engineering (PHE-338) for civil engineers at Nust Institute of Civil Engineering,H-12 sector, Islamabad, Pakistan.

Ms. Rasheed won 5000 indigenous scholarship under higher education commission-Pakistan (HEC-Pak) and one year foreign scholarship under international research support initiative Programe under HEC-Pakistan (IRSIP-HEC-Pak) for university college London (UCL), UK in the field of drinking water chlorination, chlorine decay and subsequent trihalomethane formation and their removal through granulated activated carbon (GAC) and sand dual media. The further research is in progress. 